\title{
Modified Upwind Leapfrog difference scheme *
}

\author{
A.I. Sukhinov ${ }^{1}$, A.E. Chistyakov ${ }^{1}$, I.Y. Kuznetsova ${ }^{2}$, \\ E.A. Protsenko ${ }^{3}$, Y.V. Belova ${ }^{1 * * *}$ \\ ${ }^{1}$ Don State Technical University, Rostov-on-Don, Russia \\ ${ }^{2}$ Southern Federal University, Rostov-on-Don, Russia \\ ${ }^{3}$ A.P. Chekhov University of Taganrog (branch of Rostov State University of Economics), \\ Taganrog, Russia
}

The paper considers the application of the scheme based on linear combination of the Upwind and Standard Leapfrog difference schemes with weight coefficients obtained by minimizing the approximation error. According to the resulting error estimation, it is preferable to use the proposed difference scheme with the approximation error $O\left(c h^{2}\right)$ for small Courant numbers than the classical Upwind and Standard Leapfrog difference schemes with the approximation errors $O\left(h^{2}\right)$. The paper presents the comparison solution of the transfer problem based on the proposed scheme with the results obtained using the scheme, which is the linear combination of the Upwind Leapfrog and central difference schemes, as well as two-parameter difference scheme with the third order of accuracy.

Keywords: Upwind Leapfrog scheme, Standard Leapfrog scheme, central difference scheme, twoparameter difference scheme, difference scheme accuracy.

Introduction. The paper considers numerical solution of the transfer problem based on a modified Upwind Leapfrog scheme with difference operator of which is a linear combination of the Upwind and Standard Leapfrog difference schemes [1]. Standard Leapfrog and Upwind Leapfrog difference schemes have similar properties: they are non-dissipative and have a second order of accuracy with respect to steps in the spatial and temporal coordinate directions. Despite these properties of the scheme, they have low accuracy. The modified Upwind Leapfrog scheme based on linear combination of central difference scheme and Upwind Leapfrog scheme [2] and two-parameter family of difference schemes $[3,4]$ showed the high accuracy of the numerical solution of the transfer problem.

In the linear combination of the Upwind and Standard Leapfrog difference schemes with similar properties, there is often mutual compensation for approximation errors, and the resulting scheme has better properties than the original schemes. The purpose of this work is to obtain a more accurate difference scheme based on a linear combination of the Upwind and Standard Leapfrog difference schemes.

\footnotetext{
* The reported study was funded by RFBR according to the research project 19-07-00623.
} 


\section{The Upwind and Standard Leapfrog difference schemes}

Consider the transfer equation [5]

$$
\frac{\partial q}{\partial t}+u \frac{\partial q}{\partial x}=0
$$

where $t \in[0, T], x \in[0, L], q(0, x)=q^{0}(x), q(t, 0)=0, u=$ const.

Let us introduce the uniform computational grid $\omega=\overline{\omega_{h}} \times \omega_{\tau}$, where $\bar{\omega}_{h}=\left\{x_{i} \mid x_{i}=i h, i=0,1, \ldots, N, N h=L\right\}, \omega_{\tau}=\left\{t_{j} \mid j=0,1, \ldots\right\}, \tau=t_{n+1}-t_{n}=$ const.

The following finite difference schemes can be used to solve the problem numerically:

- the Upwind Leapfrog scheme [1]:

$$
\begin{aligned}
& \frac{q_{i}^{n+1}-q_{i}^{n}}{2 \tau}+\frac{q_{i-1}^{n}-q_{i-1}^{n-1}}{2 \tau}+u \frac{q_{i}^{n}-q_{i-1}^{n}}{h}=0, u \geq 0 ; \\
& \frac{q_{i}^{n+1}-q_{i}^{n}}{2 \tau}+\frac{q_{i+1}^{n}-q_{i+1}^{n-1}}{2 \tau}+u \frac{q_{i+1}^{n}-q_{i}^{n}}{h}=0, u<0 ;
\end{aligned}
$$

- the Standard Leapfrog scheme:

$$
\frac{q_{i}^{n+1}-q_{i}^{n-1}}{2 \tau}+u \frac{q_{i+1}^{n}-q_{i-1}^{n}}{2 h}=0 .
$$

Test problem I. Find the solution of the transfer equation:

$$
\frac{\partial q}{\partial t}+u \frac{\partial q}{\partial x}=0, u=0.5 \mathrm{~m} / \mathrm{s}, 0 \leq t \leq T, 0 \leq x \leq L, q(t, 0)=0
$$

with initial conditions $q^{0}(x)=h(20-x)-h(10-x)$, where $h(x)$ is the Heaviside function.

Fig. 1 shows the numerical solutions of Test problem I based on the difference schemes (2)(3) (1 - accurate solution; 2 - numerical solution). The time step $\tau$ is equal to $0.02 \mathrm{~s}$. The space step $h$ is equal to $1 \mathrm{~m}$. The length of time interval $T$ is equal to $100 \mathrm{~s}$.

Fig. 1 ((a) and (b)) shows that the Upwind and Standard Leapfrog difference schemes have oscillations (entropic perturbations) [6]. The numerical solution based on the Upwind Leapfrog difference scheme has oscillations in the right side of the computational domain (along the pulse path). The numerical solution based on the Standard Leapfrog difference scheme has oscillations in the left part of the computational domain (behind the impulse). In the considered schemes, oscillations are generated by dispersion. In the Upwind Leapfrog scheme, high harmonics have a "phase velocity" higher than the real one, and lower for the Standard Leapfrog scheme.

Upwind and Standard Leapfrog difference schemes are non-dissipative and, for this reason, not monotonic. That's why these schemes are not recommended for use in transfer problems with discontinuous initial data without artificial viscosity or other monotonizing solution procedures. For the Upwind Leapfrog scheme, it's recommended to use nonlinear flow correction (limiters) [7-9] based on the maximum principle. The solutions of Test problem I based on the Upwind and Standard Leapfrog difference schemes with limiters are shown in Fig. 1 ((c) and (d)). 

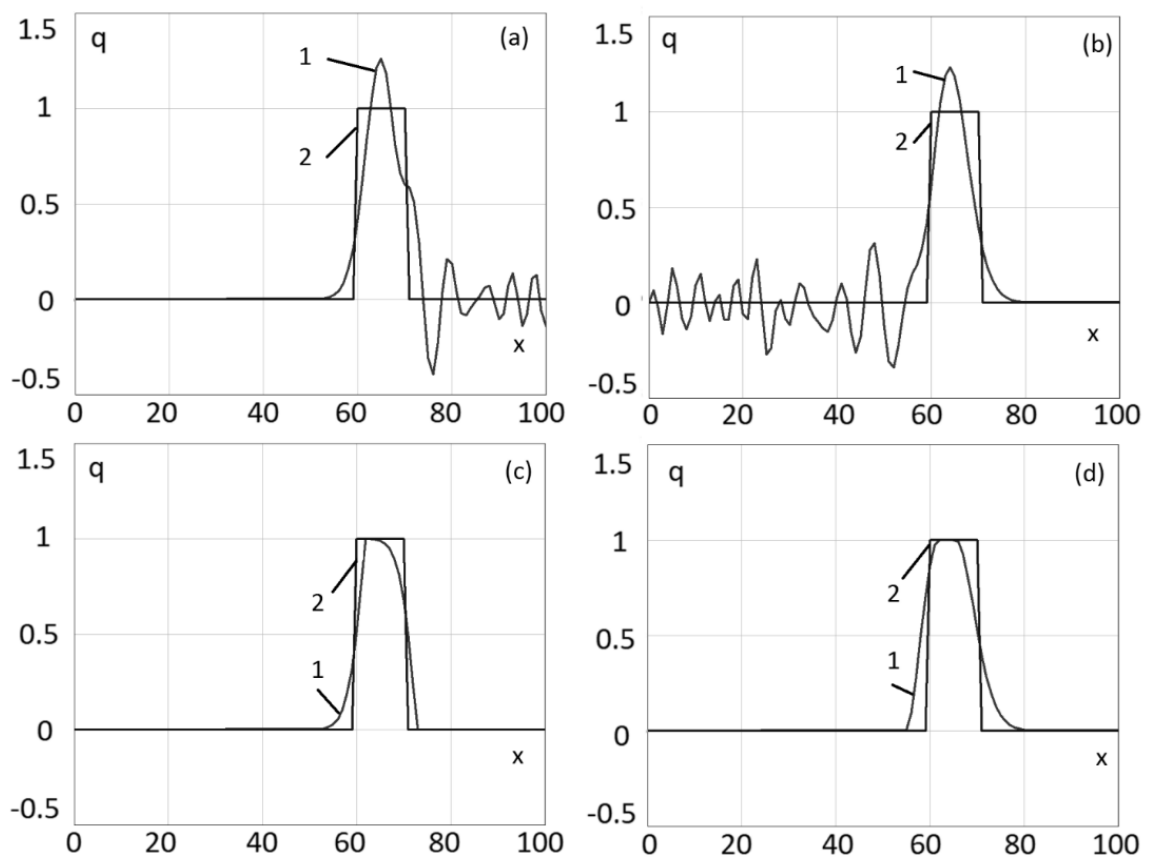

Fig. 1. Solutions of Test problem I based on the difference schemes:

(a) the Upwind Leapfrog scheme (2); (b) the Standard Leapfrog scheme (3);

(c) the Upwind Leapfrog scheme with limiters [7-9];

(d) the Standard Leapfrog scheme with limiters [7-9]

\section{Linear combination of the Upwind and Standard Leapfrog difference schemes}

Consider the Upwind Leapfrog difference scheme (case $u \geq 0$ ):

$$
\frac{q_{i}^{n+1}-q_{i}^{n}}{2 \tau}+\frac{q_{i-1}^{n}-q_{i-1}^{n-1}}{2 \tau}+u \frac{q_{i}^{n}-q_{i-1}^{n}}{h}=0 .
$$

We use the decompositions of the functions $q_{i}^{n \pm 1}$ and $q_{(i-1 / 2) \pm 1 / 2}^{n}$ in the Taylor series in the neighborhood of points $(i, n)$ and $(i-1 / 2, n)$, respectively:

$$
\begin{gathered}
q_{i}^{n \pm 1}=q_{i}^{n} \pm \tau\left(q_{t}\right)_{i}^{n}+\frac{\tau^{2}}{2}\left(q_{t t}\right)_{i}^{n} \pm \frac{\tau^{3}}{3 !}\left(q_{t t t}\right)_{i}^{n}+\frac{\tau^{4}}{4 !}\left(q_{t t t t}\right)_{i}^{n}+O\left(\tau^{5}\right) \\
q_{(i-1 / 2) \pm 1 / 2}^{n}=q_{i-1 / 2}^{n} \pm \frac{h}{2}\left(q_{x}\right)_{i-1 / 2}^{n}+ \\
+\frac{h^{2}}{8}\left(q_{x x}\right)_{i-1 / 2}^{n} \pm \frac{h^{3}}{48}\left(q_{x x x}\right)_{i-1 / 2}^{n}+\frac{h^{4}}{384}\left(q_{x x x x}\right)_{i-1 / 2}^{n}+O\left(h^{5}\right) .
\end{gathered}
$$

We substituted (5) and (6) in (4):

$$
\begin{aligned}
\frac{q_{i}^{n+1}-q_{i}^{n}}{2 \tau}+\frac{q_{i-1}^{n}-q_{i-1}^{n-1}}{2 \tau} & +u \frac{q_{i}^{n}-q_{i-1}^{n}}{h}=\left(q_{t}\right)_{i-1 / 2}^{n}+u\left(q_{x}\right)_{i-1 / 2}^{n}-\frac{u h^{2}}{12}\left(q_{x x x}\right)_{i-1 / 2}^{n}+ \\
& +\frac{u^{2} \tau h}{4}\left(q_{x x x}\right)_{i-1 / 2}^{n}-\frac{u^{3} \tau^{2}}{6}\left(q_{x x x}\right)_{i-1 / 2}^{n}+O\left(h^{4}\right) .
\end{aligned}
$$

In view of (1)

$$
q_{t}=-u q_{x}, q_{t t}=u^{2} q_{x x}, q_{t t t}=-u^{3} q_{x x x}, q_{t t t t}=u^{4} q_{x x x x}
$$


the expression (7) takes the form:

$$
\begin{gathered}
\frac{q_{i}^{n+1}-q_{i}^{n}}{2 \tau}+\frac{q_{i-1}^{n}-q_{i-1}^{n-1}}{2 \tau}+u \frac{q_{i}^{n}-q_{i-1}^{n}}{h}= \\
=\left(q_{t}+u q_{x}\right)_{i-1 / 2}^{n}-\frac{(c-1)(2 c-1)}{12} u h^{2}\left(q_{x x x}\right)_{i-1 / 2}^{n}+O\left(h^{4}\right) .
\end{gathered}
$$

Let consider the Standard Leapfrog difference scheme (3). We use the decompositions of the function $q_{i \pm 1}^{n}$ in the Taylor series in the neighborhood of points $(i, n)$ :

$$
q_{i \pm 1}^{n}=q_{i}^{n} \pm h\left(q_{x}\right)_{i}^{n}+\frac{h^{2}}{2}\left(q_{x x}\right)_{i}^{n} \pm \frac{h^{3}}{3 !}\left(q_{x x x}\right)_{i}^{n}+\frac{h^{4}}{4 !}\left(q_{x x x x}\right)_{i}^{n}+O\left(h^{5}\right) .
$$

We substituted (10) and (5) in (3):

$$
\begin{gathered}
\frac{q_{i}^{n+1}-q_{i}^{n-1}}{2 \tau}+u \frac{q_{i+1}^{n}-q_{i-1}^{n}}{2 h}= \\
=\left(q_{t}\right)_{i}^{n}+\frac{\tau^{2}}{6}\left(q_{t t t}\right)_{i}^{n}+u\left(q_{x}\right)_{i}^{n}+u \frac{h^{2}}{6}\left(q_{x x x}\right)_{i}^{n}+O\left(\tau^{4}+h^{4}\right) .
\end{gathered}
$$

In view of (8), expression (11) takes the form:

$$
\frac{q_{i}^{n+1}-q_{i}^{n-1}}{2 \tau}+u \frac{q_{i+1}^{n}-q_{i-1}^{n}}{2 h}=\left(q_{t}+u q_{x}\right)_{i}^{n}+\frac{1-c^{2}}{6} u h^{2}\left(q_{x x x}\right)_{i}^{n}+O\left(h^{4}\right) .
$$

Consider the difference scheme, which is a linear combination of the Upwind and Standard Leapfrog difference schemes with weights $2 / 3$ and $1 / 3$, respectively

$$
\begin{aligned}
& \frac{q_{i}^{n+1}-q_{i}^{n}}{\tau}+\frac{4}{3}\left(\frac{q_{i-1}^{n}-q_{i-1}^{n-1}}{2 \tau}+u \frac{q_{i}^{n}-q_{i-1}^{n}}{h}\right)+\frac{q_{i}^{n}-q_{i}^{n-1}}{3 \tau}+u \frac{q_{i+1}^{n}-q_{i-1}^{n}}{3 h}=0, u \geq 0 \\
& \frac{q_{i}^{n+1}-q_{i}^{n}}{\tau}+\frac{4}{3}\left(\frac{q_{i+1}^{n}-q_{i+1}^{n-1}}{2 \tau}+u \frac{q_{i+1}^{n}-q_{i}^{n}}{h}\right)+\frac{q_{i}^{n}-q_{i}^{n-1}}{3 \tau}+u \frac{q_{i+1}^{n}-q_{i-1}^{n}}{3 h}=0, u<0 .
\end{aligned}
$$

According to (8), (9) and (12) the scheme (13) has a local approximation error equaled to $\frac{c(1-c)}{6} u h^{2} q_{x x x}+O\left(h^{3}\right)$ relative to the fictional node $(i-1 / 3, n)$.

According to the resulting error estimation, it is preferable to use the scheme (13) with the approximation error $O\left(c h^{2}\right)$ for small Courant numbers than the classical Upwind and Standard Leapfrog difference schemes with the approximation errors $O\left(h^{2}\right)$.

Fig. 2 shows the numerical solutions of Test problem I based on the difference scheme (13) ( 1 - accurate solution; 2 - numerical solution). The time step $\tau$ is equal to $0.02 \mathrm{~s}$. The space step $h$ is equal to $1 \mathrm{~m}$. The lengths of time interval $T$ are equal to $100 \mathrm{~s}$ and $900 \mathrm{~s}$. 

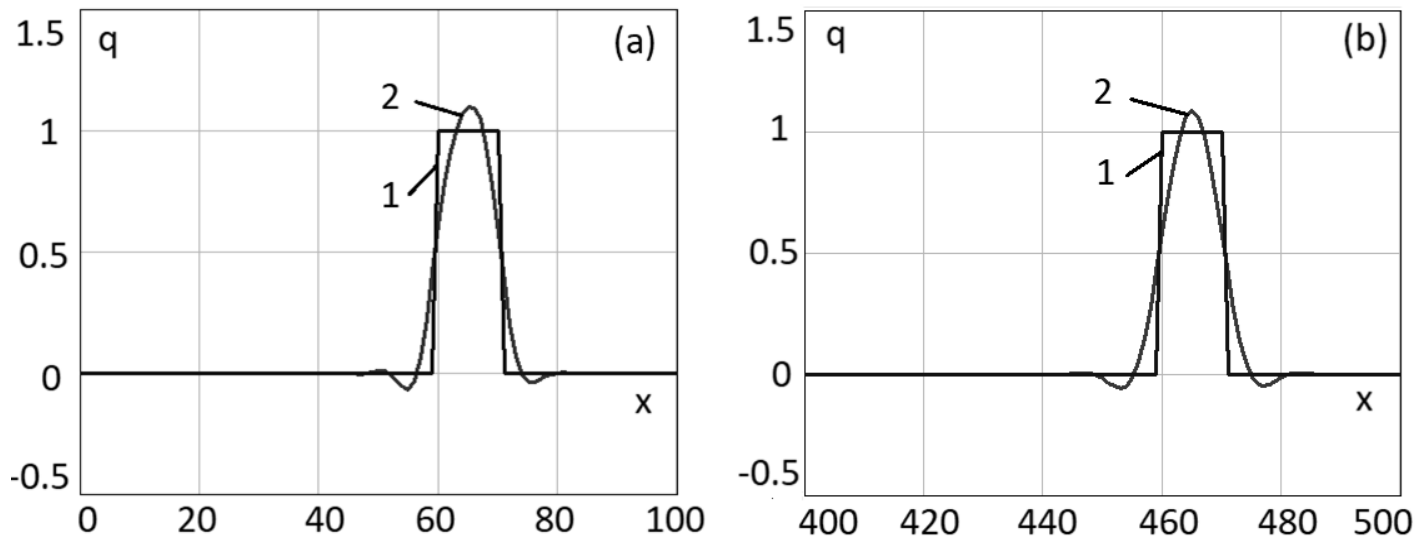

Fig. 2. Solutions of Test problem I for different lengths of time interval $T$ :

(a) $T=100 \mathrm{~s}$; (b) $T=500 \mathrm{~s}$

Test problem II. Find the solution of the equation

$$
\begin{gathered}
\frac{\partial q}{\partial t}+u \frac{\partial q}{\partial x}=\mu \frac{\partial^{2} q}{\partial x^{2}}, u=0.5 \mathrm{~m} / \mathrm{s}, \mu=\text { const } \\
0 \leq t \leq T, 0 \leq x \leq L, q(t, 0)=q(t, L)=0
\end{gathered}
$$

with initial conditions $q^{0}(x)=h(20-x)-h(10-x)$, where $h(x)$ is the Heaviside function.

The analytical solution of Test problem II is written in the form [11]:

$$
q(t, x)=\sum_{m=1}^{N-1} c_{m}^{0} e^{-\mu \omega^{2} m^{2} t} \sin (\omega m x), c_{m}^{0}=\frac{2}{L} \int_{0}^{l} q^{0}(x+u t) \sin (\omega m x) d x, \omega=\frac{\pi}{L} .
$$

Fig. 3 shows solutions of Test problem II (1 - analytical (accurate) solution; 2 - numerical solution based on the difference scheme (13); 3 - numerical solution based on the Upwind Leapfrog scheme with limiters). In case (a), parameter $\mu$ is equal to $0.025 \mathrm{~m}^{2} / \mathrm{s}$ and grid Peclet number [4] $(P e=u h / \mu)$ is equal to 20. In case (b), $\mu=0.0025 \mathrm{~m}^{2} / \mathrm{s}$ and grid Peclet number $P e=200$.
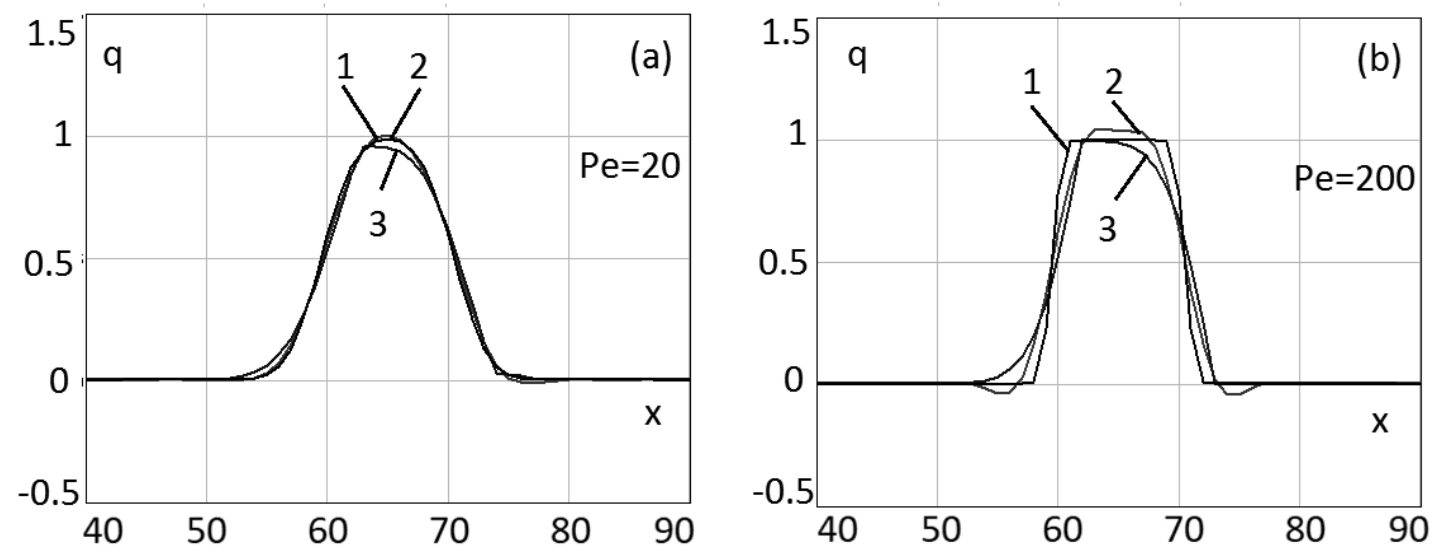

Fig. 3. Solutions of Test problem II for different values of grid Peclet number:

(a) $P e=20$; (b) $P e=200$ 
Fig. 4 shows the errors $\Psi^{n}$ of the numerical solution of Test problem II based on the difference scheme (13) and the Upwind Leapfrog difference schemes with limiters in the norm $L_{1}$, which depends on the value of grid Peclet number.

The solution error is calculated using the formula $\Psi=\sqrt{\sum_{i}\left(\tilde{q}_{i}-q_{i}\right)^{2} / \sum_{i} q_{i}^{2}}$, where $q_{i}$ is the exact solution value of the diffusion problem in the node $i, \tilde{q}_{i}$ is the numerical solution that depends on the time step value [6].

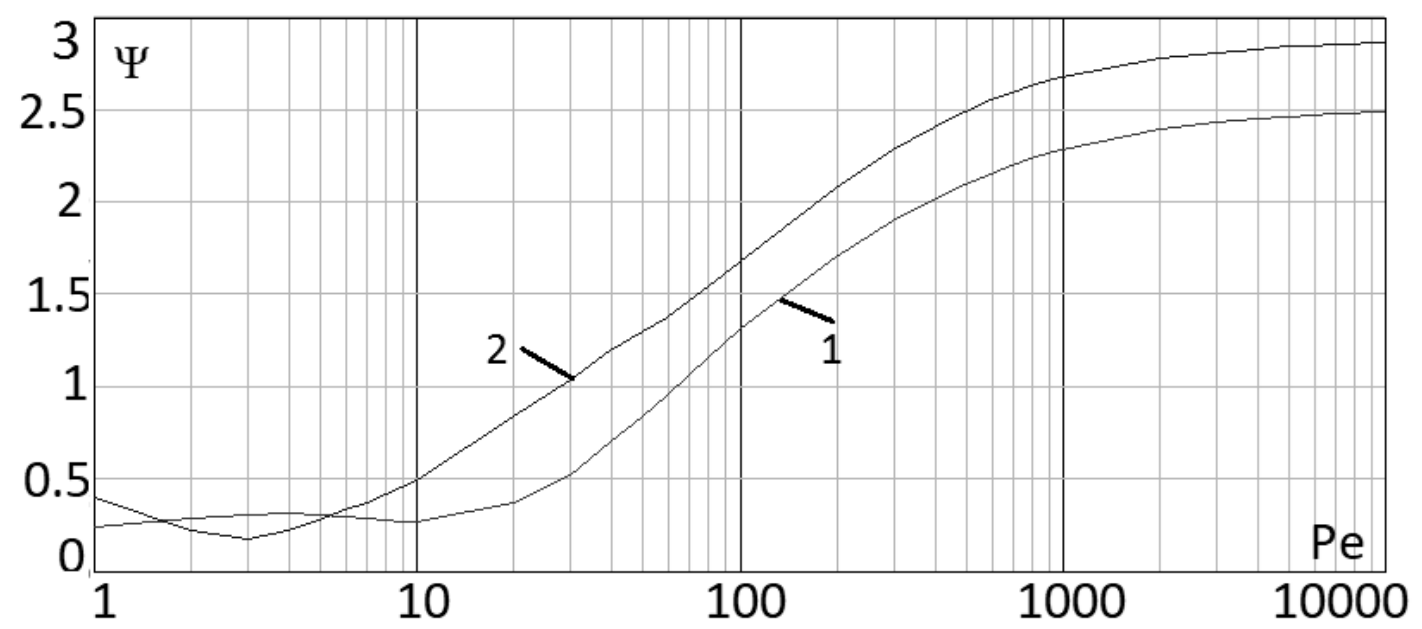

Fig. 4. Functions of approximation error for Test problem II in the norm $L_{1}$, which depends on the value of grid Peclet number:

1 - solution based on the difference scheme (13);

2 - solution based on the Upwind Leapfrog scheme with limiters

Fig. 3 and 4 show that the proposed difference scheme (13) for solving Test problem II has a smaller error in a wide range of grid Peclet numbers.

Analytical solution of the convection-diffusion equation. Consider the initial-boundary value problem for a parabolic equation

$$
q_{t}^{\prime}+u q_{x}^{\prime}=\mu q_{x x}^{\prime \prime}
$$

with initial conditions

$$
q(0, x)=q^{0}(x)
$$

and boundary conditions

$$
q(t, 0)=q(t, L)=0,
$$

where $t \in[0, T], x \in[0, L], u=$ const, $\mu=$ const.

Find solution for

$$
q(x, t) \in C^{2}(0<x<L) \cap C(0 \leq x \leq L) \cap C^{1}(0<t<+\infty) \cap C(0 \leq t<+\infty) .
$$

Write the finite sum of the trigonometric Fourier series for the function $q(x, t)$ in complex form: 


$$
q(x, t)=\sum_{m=-N}^{N} C_{m}(t) \exp (j \omega m x)
$$

where $\omega=\frac{\pi}{L}, m$ is number of mode, $C_{m}(t)=\frac{2}{L} \int_{0}^{L} q(x, t) \exp (j \omega m x) d x$ is complex amplitude of the $m$-th mode, $j=\sqrt{-1}$.

Substitute (17) in (14):

$$
\begin{gathered}
\left(\sum_{m=-N}^{N} C_{m}(t) \exp (j \omega m x)\right)_{t}^{\prime}+u\left(\sum_{m=-N}^{N} C_{m}(t) \exp (j \omega m x)\right)_{x}^{\prime}= \\
=\mu\left(\sum_{m=-N}^{N} C_{m}(t) \exp (j \omega m x)\right)_{x x}^{\prime \prime} .
\end{gathered}
$$

Change the sequence of differentiation and summation of a series, calculate the derivative with respect to space:

$$
\begin{gathered}
\sum_{m=-N}^{N}\left(C_{m}(t)\right)_{t}^{\prime} \exp (j \omega m x)+j u \omega m \sum_{m=-N}^{N} C_{m}(t) \exp (j \omega m x)= \\
=-\mu \omega^{2} m^{2} \sum_{m=-N}^{N} C_{m}(t) \exp (j \omega m x)
\end{gathered}
$$

The functions $\exp (j \omega m x)$ are linearly independent, therefore

$$
\left(C_{m}(t)\right)_{t}^{\prime}=-\left(j u \omega m+\mu \omega^{2} m^{2}\right) C_{m}(t) .
$$

The solution of equation (18) has the form:

$$
C_{m}(t)=C_{m}(0) \exp \left(-\left(\mu \omega^{2} m^{2}+j u \omega m\right) t\right) .
$$

Substituting (19) into (18) and using the initial and boundary conditions (15)-(16), we obtain a solution to equation (14):

$$
q(x, t)=\sum_{m=-N}^{N} C_{m}(0) \exp \left(-\left(\mu \omega^{2} m^{2}+j u \omega m\right) t\right) \exp (j \omega m x) .
$$

Accuracy of difference scheme. For numerical solution of the problem (14), we covered the computational domain by a uniform grid $\omega=\omega_{\tau} \times \bar{\omega}_{x}$, where $\bar{\omega}_{x}=\left\{x_{i} \mid x_{i}=i h ; i=\overline{0, N_{x}} ; N_{x} h=L\right\}$; $\omega_{\tau}=\left\{t^{n} \mid t^{n}=n \tau ; n=\overline{0, N_{t}} ; N_{t} \tau=T\right\} ; \tau$ is the time step; $h$ is the space step; $N_{t}$ is the number of nodes in time; $N_{x}$ is the number of nodes in space.

The approximation of equation (14) has the form

$$
\frac{q_{i}^{n+1}-q_{i}^{n}}{\tau}+\frac{4}{3}\left(\frac{q_{i-1}^{n}-q_{i-1}^{n-1}}{2 \tau}+u \frac{q_{i}^{n}-q_{i-1}^{n}}{h}\right)+\frac{q_{i}^{n}-q_{i}^{n-1}}{3 \tau}+u \frac{q_{i+1}^{n}-q_{i-1}^{n}}{3 h}=\frac{q_{i+1}^{n}-2 q_{i}^{n}+q_{i-1}^{n}}{h^{2}}
$$

or

$$
\frac{q_{i}^{n+1}-q_{i}^{n}}{\tau}+2 \frac{q_{i-1}^{n}-q_{i-1}^{n-1}}{3 \tau}+\frac{q_{i}^{n}-q_{i}^{n-1}}{3 \tau}+
$$




$$
+u \frac{q_{i+1}^{n}+4 q_{i}^{n}-5 q_{i-1}^{n}}{3 h}-2 \mu \frac{q_{i+1}^{n}-2 q_{i}^{n}+q_{i-1}^{n}}{h^{2}}=0,
$$

where

$$
q_{i}=\sum_{m=-N}^{N} C_{m} \exp \left(j m \omega x_{i}\right)
$$

Substitute (22) in (21):

$$
\begin{gathered}
\sum_{m=-N}^{N} \frac{C_{m}^{n+1} \exp (j \omega m h i)-C_{m}^{n} \exp (j \omega m h i)}{\tau}+ \\
+2 \sum_{m=-N}^{N} \frac{C_{m}^{n} \exp (j m \omega h(i-1))-C_{m}^{n-1} \exp (j m \omega h(i-1))}{3 \tau}+ \\
+\sum_{m=-N}^{N} \frac{C_{m}^{n} \exp (j m \omega h i)-C_{m}^{n-1} \exp (j m \omega h i)}{3 \tau}+ \\
-2 \mu \sum_{m=-N}^{N} \frac{C_{m}^{n} \exp (j \omega m h(i+1))+4 C_{m}^{n} \exp (j \omega m h i)-5 C_{m}^{n} \exp (j \omega m h(i-1))}{3 h}- \\
C_{m}^{n} \exp (j \omega m h(i+1))-2 C_{m}^{n} \exp (j \omega m h i)+C_{m}^{n} \exp (j \omega m h(i-1)) \\
h^{2}
\end{gathered}
$$

By making some simple arithmetic, we get:

$$
\begin{gathered}
\sum_{m=-N}^{N} \frac{C_{m}^{n+1}-C_{m}^{n}}{\tau} \exp (j \omega m h i)+2 \sum_{m=-N}^{N} \frac{C_{m}^{n}-C_{m}^{n-1}}{3 \tau} \exp (-j \omega m h) \exp (j \omega m h i)+ \\
+\sum_{m=-N}^{N} \frac{C_{m}^{n}-C_{m}^{n-1}}{3 \tau} \exp (j \omega m h i)+ \\
+u \sum_{m=-N}^{N} \frac{C_{m}^{n} \exp (j \omega m h)+4 C_{m}^{n}-5 C_{m}^{n} \exp (-j \omega m h)}{3 h} \exp (j \omega m h i)- \\
-2 \mu \sum_{m=-N}^{N} \frac{C_{m}^{n} \exp (j \omega m h)-2 C_{m}^{n}+C_{m}^{n} \exp (-j \omega m h)}{h^{2}} \exp (j \omega m h i)=0 .
\end{gathered}
$$

The functions $\exp (j m \omega i)$ are linearly independent, therefore

$$
\begin{gathered}
\frac{C_{m}^{n+1}-C_{m}^{n}}{\tau}+2 \frac{C_{m}^{n}-C_{m}^{n-1}}{3 \tau} \exp (-j \omega m h)+\frac{C_{m}^{n}-C_{m}^{n-1}}{3 \tau}+ \\
+u C_{m}^{n} \frac{\exp (j \omega m h)+4-5 \exp (-j \omega m h)}{3 h}- \\
\quad-2 \mu C_{m}^{n} \frac{\exp (j \omega m h)-2+\exp (-j \omega m h)}{h^{2}}=0 .
\end{gathered}
$$

when $\tau \rightarrow 0$, (25) takes form:

$$
\left(C_{m}(t)\right)_{t}^{\prime}\left(\frac{4}{3}+2 \frac{\exp (-j \omega m h)}{3}\right)+u C_{m}^{n} \frac{\exp (j \omega m h)+4-5 \exp (-j \omega m h)}{3 h}-
$$




$$
-2 \mu C_{m}^{n} \frac{\exp (j \omega m h)-2+\exp (-j \omega m h)}{h^{2}}=0
$$

or

$$
\begin{aligned}
\left(C_{m}(t)\right)_{t}^{\prime} & =\left(-u \frac{\exp (j \omega m h)+4-5 \exp (-j \omega m h)}{2 h(2+\exp (-j \omega m h))}+\right. \\
& \left.+\mu \frac{3(\exp (j \omega m h)-2+\exp (-j \omega m h))}{h^{2}(2+\exp (-j \omega m h))}\right) C_{m}^{n} .
\end{aligned}
$$

Lemma. When approximating problem (14) by difference scheme (21) for each mode of solution function $q$, the convective exchange $u$ and diffusion exchange $\mu$ rates are less than real values and differ by

and

$$
\alpha_{1}=1-\frac{\exp (j \omega m h)+4-5 \exp (-j \omega m h)}{2 j \omega m h(2+\exp (-j \omega m h))}
$$

$$
\alpha_{2}=1-\frac{3(-\exp (j \omega m h)+2-\exp (-j \omega m h))}{\omega^{2} m^{2} h^{2}(2+\exp (-j \omega m h))},
$$

respectively.

Proof. Using (25), when $\tau \rightarrow 0$, we obtain:

$$
\begin{gathered}
\left(C_{m}(t)\right)_{t}^{\prime}=\left(-j u \omega m \frac{\exp (j \omega m h)+4-5 \exp (-j \omega m h)}{2 j \omega m h(2+\exp (-j \omega m h))}+\right. \\
\left.+\mu \omega^{2} m^{2} \frac{3(\exp (j \omega m h)-2+\exp (-j \omega m h))}{\omega^{2} m^{2} h^{2}(2+\exp (-j \omega m h))}\right) C_{m}^{n} .
\end{gathered}
$$

Using (18), the solution based on difference scheme (21) corresponds to the solution of the equation $q_{t}^{\prime}=-u^{*} q_{x}^{\prime}+\mu^{*} q_{x x}^{\prime \prime}$, where $u^{*}=u\left(1-\alpha_{1}\right), \mu^{*}=\mu\left(1-\alpha_{2}\right)$,

$$
\alpha_{1}=1-\frac{\exp (j \omega m h)+4-5 \exp (-j \omega m h)}{2 j \omega m h(2+\exp (-j \omega m h))}, \alpha_{2}=1-\frac{3(-\exp (j \omega m h)+2-\exp (-j \omega m h))}{\omega^{2} m^{2} h^{2}(2+\exp (-j \omega m h))} \text {, }
$$

q.e.d.

Analyze the approximation error of the convective term in space. Change the variable $j \omega m h=s$, when

$$
\begin{gathered}
\alpha_{1}=1-\frac{e^{s}+4-5 e^{-s}}{2 s\left(2+e^{-s}\right)}= \\
=1-\frac{1+s+\frac{s^{2}}{2}+\frac{s^{3}}{6}+\frac{s^{4}}{24}+O\left(s^{5}\right)+4-5+5 s-\frac{5 s^{2}}{2}+\frac{5 s^{3}}{6}-\frac{5 s^{4}}{24}+O\left(s^{5}\right)}{2 s\left(2+1-s+\frac{s^{2}}{2}-\frac{s^{3}}{6}+\frac{s^{4}}{24}+O\left(s^{5}\right)\right)}=
\end{gathered}
$$




$$
\begin{aligned}
& =\frac{-\frac{s^{4}}{12}+\frac{s^{5}}{12}+O\left(s^{6}\right)}{6 s-2 s^{2}+s^{3}-\frac{s^{4}}{3}+\frac{s^{5}}{12}+O\left(s^{6}\right)}=-\frac{s^{3}}{72}+O\left(s^{4}\right) \\
& \alpha_{1}=j \frac{(\omega m h)^{3}}{73}+O\left((\omega m h)^{4}\right) .
\end{aligned}
$$

From the expression (27) we can obtain that the scheme (21) approximates the convective term with the third order of accuracy in space.

Analyze the approximation error of the diffusion term in space:

$$
\begin{gathered}
\alpha_{2}=1+\frac{-3 e^{s}+6-3 e^{-s}}{s^{2}\left(2+e^{-s}\right)}= \\
=1-\frac{3+3 s+\frac{3 s^{2}}{2}+\frac{3 s^{3}}{6}+\frac{3 s^{4}}{24}+O\left(s^{5}\right)-6+3-3 s+\frac{3 s^{2}}{2}-\frac{3 s^{3}}{6}+\frac{3 s^{4}}{24}+O\left(s^{5}\right)}{s^{2}\left(2+1-s+\frac{s^{2}}{2}-\frac{s^{3}}{6}+\frac{x^{4}}{24}+O\left(s^{5}\right)\right)}= \\
=1-\frac{3 s^{2}+\frac{3 s^{4}}{12}+O\left(s^{5}\right)}{3 s^{2}-s^{3}+s^{4} / 2+O\left(s^{5}\right)}=\frac{3 s^{2}-s^{3}+s^{4} / 2+O\left(s^{5}\right)-3 s^{2}-s^{4} / 4+O\left(s^{5}\right)}{3 s^{2}-s^{3}+s^{4} / 2+O\left(s^{5}\right)}= \\
=\frac{-s^{3}+s^{4} / 4+O\left(s^{5}\right)}{6 s^{2}-2 s^{3}+s^{4}+O\left(s^{5}\right)}=-\frac{s}{6}+O\left(s^{2}\right) .
\end{gathered}
$$

Note that the variable $r=\pi / \omega m h$ describes the number of nodes per half wave period, and $\pi>\omega m h$. Therefore, the solution accuracy depends on the number of nodes per half wave period.

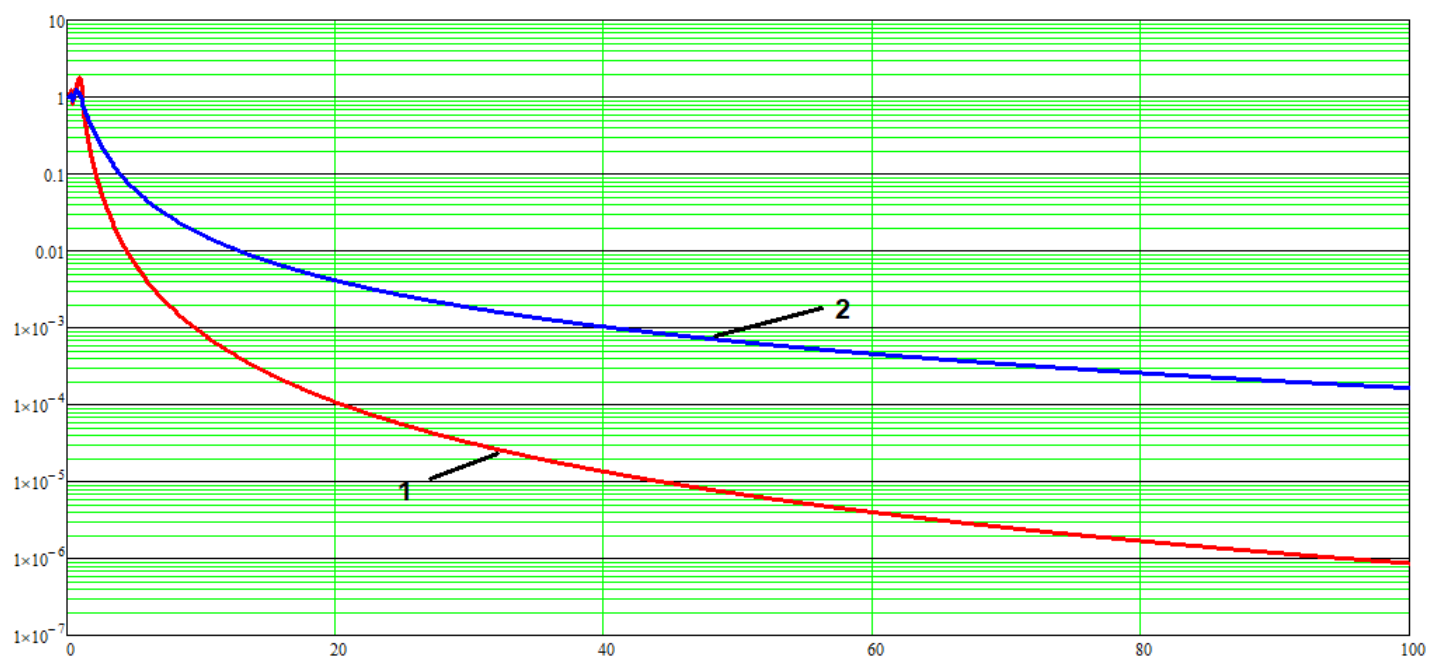

Fig. 5. The dependence of the approximation error of the convective term on the number of nodes: 1 - difference scheme (21); 2 - central difference scheme 
Fig. 5 and 6 show functions $\quad \alpha_{1}(r)=1-\frac{\exp (j \pi / r)+4-5 \exp (-j \pi / r)}{2 j \pi / r(2+\exp (-j \pi / r))}$, $\alpha_{2}(r)=1-\frac{3(-\exp (j \pi / r)+2-\exp (-j \pi / r))}{\pi^{2} / r^{2}(2+\exp (-j \pi / r))}$ that describe the dependence of the approximation error of the convective and diffusion terms, respectively, by the difference scheme (21) on the number of nodes in comparison with the central difference scheme [1].

Analyzing Fig. 5 and 6, we can conclude that linear combination of the central difference scheme and the Upwind Leapfrog scheme (21) is applicable for problems in which convective transport prevails over diffusion.

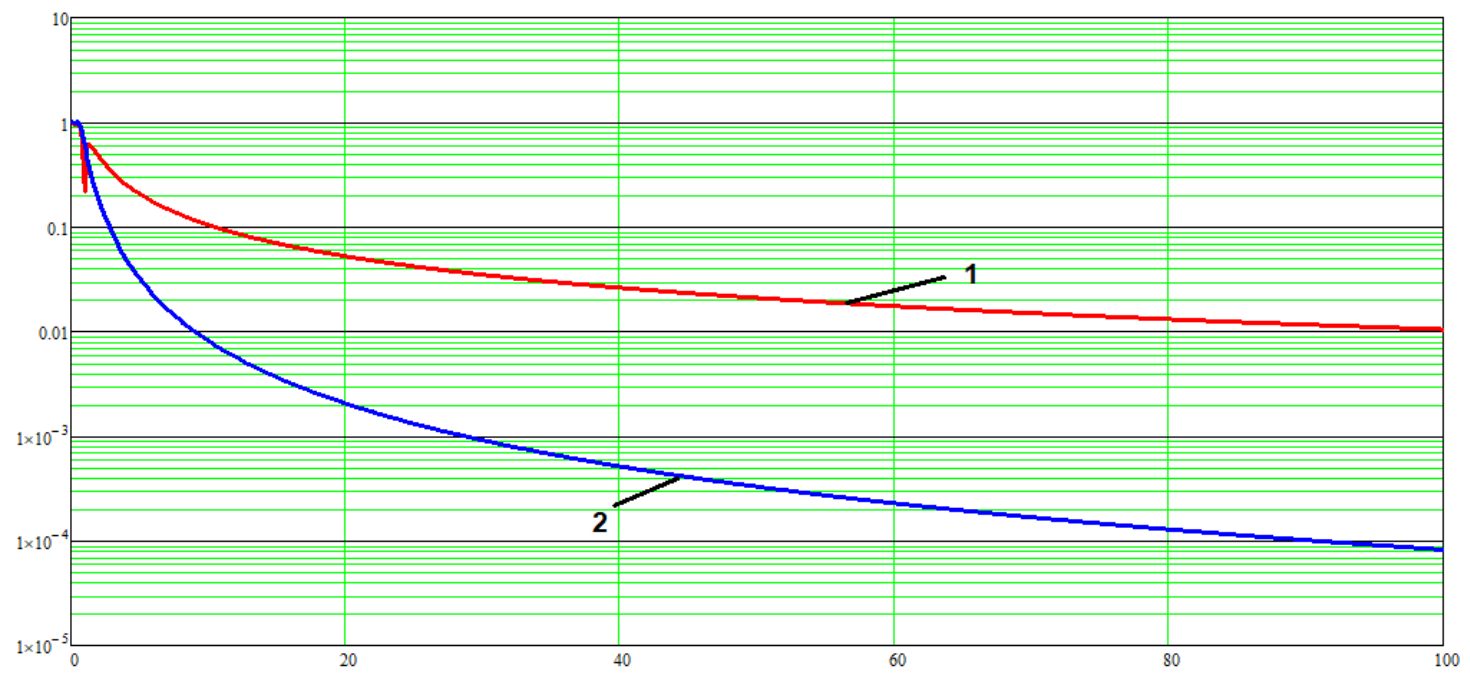

Fig. 6. The dependence of the approximation error of the diffusion term on the number of nodes: 1 difference scheme (21); 2 - central difference scheme

Conclusion. Solution of the transfer equation based on the Upwind Leapfrog difference scheme has oscillations in the right side of the computational domain (along the path of the pulse). Solution of the transfer equation based on the Standard Leapfrog difference scheme has oscillations in the left part of the computational domain (behind the impulse). In the considered schemes, oscillations are generated by dispersion. In the Upwind Leapfrog scheme, high harmonics have a «phase velocity» higher than the real one, and lower for the Standard Leapfrog scheme. Mesh refinement leads to a linear increase in the number of layers over time. From the obtained results, we can conclude that the accuracy of numerical solution of the transport equation based on the Upwind Leapfrog difference scheme at small Courant numbers does not increase with decreasing time step.

The paper presents the modified Upwind Leapfrog difference scheme which is a linear combination of the Upwind and Standard Leapfrog difference schemes with weight coefficients $2 / 3$ and $1 / 3$, respectively, calculated by minimizing the order of approximation error to solve the transport problem. According to the resulting error estimation, it is preferable to use the proposed difference 
scheme with the approximation error $O\left(c h^{2}\right)$ for small Courant numbers than the classical Upwind and Standard Leapfrog difference schemes with the approximation errors $O\left(h^{2}\right)$.

The paper presents the comparison solution of the transfer problem based on the proposed scheme with the results obtained using the scheme, which is the linear combination of the Upwind Leapfrog and central difference schemes, as well as two-parameter difference scheme with the third order of accuracy. In the norm of the grid space $L_{1}$, the dependences of the numerical solution errors of the model transport problems based on the above schemes depending on the values of the Courant numbers are given.

According to the presented examples, it follows that for small Courant numbers ( 0.1 or less) of the proposed scheme, as well as scheme, which is the linear combination of the Upwind Leapfrog and central difference schemes, is more accurate than the others considered in the work. But proposed scheme has a stable solution in the range of Courant numbers from 0 to 1 (the difference scheme obtained as a result of a linear combination of the central difference scheme and the Upwind Leapfrog scheme does not have this property). For the unsteady convection-diffusion equation, the proposed difference scheme has a small error in a wide range of grid Peclet numbers.

\section{References}

1. Goloviznin, V.M., Samarskii, A.A. Finite difference approximation of convective transport equation with space splitting time derivative // Math. Models and Comput. Simul. - 1998. - Vol. 10, № 1. P. 86-100 (in Russian).

2. Sukhinov, A.I., Chistyakov, A.E. Cabaret Difference Scheme with Improved Dispersion Properties // Math. Models and Comput. Simul. - 2019. - Vol. 11, № 6. - P. 867-876. DOI: 10.1134/S207004821906019X

3. Gushchin, V.A. Family of quasi-monotonic finite-difference schemes of the second-order of approximation // Math. Models and Comput. Simul. - 2016. - Vol. 8. - P. 487-496. DOI: $10.1134 /$ S2070048216050094

4. Belotserkovskii, O.M., Gushchin, V.A., Kon'shin, V.N. The splitting method for investigating flows of a stratified liquid with a free surface // Comput. Math. Math. Phys. - 1987. - Vol. 27, № 2. - P. 181191.

5. Samarskiy, A.A., Vabishchevich, P.N. Numerical methods for solving convection-diffusion problems. - Moscow: URSS. - 1999. - 248 p. (in Russian).

6. Ladonkina, M.E., Neklyudova, O.A., Tishkin, V.F. Application of the RKDG method for gas dynamics problems // Math. Models and Comput. Simul. -2014. - Vol. 6, № 4. - P. 397-407. DOI: $10.1134 / \mathrm{S} 207004821404005 \mathrm{X}$

7. Samarskii, A.A. On the regularization of difference schemes // U.S.S.R. Comput. Math. Math. Phys. - 1967. - Vol. 7, № 1. - P. 62-93.

8. Samarskii, A.A. Classes of stable schemes // U.S.S.R. Comput. Math. Math. Phys. - 1967. Vol. 7, № 5. - P. 171-223.

9. Fedorenko, R.P. The application of difference schemes of high accuracy to the numerical solution of hyperbolic equations // U.S.S.R. Comput. Math. Math. Phys. - 1963. - Vol. 2, № 6. - P. 13551365 .

10. Sukhinov, A.I., Chistyakov, A.E., Shishenya, A.V., Timofeeva, E.F. Mathematical model for calculating coastal wave processes // Math. Models and Comput. Simul. - 2013. - Vol. 5, №. 5. - P. 122-129.

11. Sukhinov, A.I., Chistakov, A.E., Iakobovskii, M.V. Accuracy of the Numerical Solution of the Equations of Diffusion-Convection Using the Difference Schemes of Second and Fourth Order Approximation Error // Vestn. YuUrGU. Ser. Vych. Matem. Inform. -2016. - Vol. 5, № 1. - P. 47-62. 
Authors:

Sukhinov Alexander Ivanovich, Don State Technical University, (Gagarin square, 1, Rostov-onDon, Russia), Doctor of Science in Physics and Maths, Full professor, Head of a department. Email address: sukhinov@gmail.com, ORCID: 0000-0002-5875-1523

Chistyakov Alexander Evgenyevich, Don State Technical University, (Gagarin square, 1, Rostovon-Don, Russia), Doctor of Science in Physics and Maths, Professor. Email address: cheese_05@mail.ru

Kuznetsova Inna Yurevna, Southern Federal University, (Bolshaya Sadovaya Str., 105/42, Rostovon-Don, Russia), Senior lector. Email address: ikuznetsova@sfedu.ru, ORCID: 0000-0003-19961605

Protsenko Elena Anatolyevna, A.P. Chekhov University of Taganrog (branch of Rostov State University of Economics, Initsiativnaya Str. 48, Taganrog, Russia), Candidate of Science in Physics and Maths, Assistant professor. Email address: eapros@rambler.ru

Belova Yulia Valerievna, Don State Technical University, (Gagarin square, 1, Rostov-on-Don, Russia), Candidate of Science in Physics and Maths. Email address: yvbelova@yandex.ru 


\section{Модифицированная схема «кабаре»*}

\section{А.И. Сухинов ${ }^{1}$, А.Е. Чистяков ${ }^{1}$, И.Ю. Кузнецова ${ }^{2}$,}

Е.А. Проценко ${ }^{3}$ Ю.В. Белова ${ }^{1}$

1 Донской государственный технический университет, Ростов-на-Дону, Российская Федерация

${ }^{2}$ Южный федеральный университет, Ростов-на-Дону, Российская Федерация

${ }^{3}$ Таганрогский институт имени А.П. Чехова (филиал) ФГБОУ ВО «РГЭУ (РИНХ)», Таганрог, Российская Федерация

В работе рассматривается применение разностной схемы, построенной на основе линейной комбинации разностной схемы «кабаре» и «крест» с весовыми коэффициентами, полученными в результате минимизации погрешности аппроксимации. Получена оценка погрешности аппроксимации для предложенной разностной схемы из которой следует, что при малых числах Куранта данную схему, имеющую погрешность аппроксимации $O\left(c h^{2}\right)$, предпочтительней использовать, чем исходные схемы «кабаре» и «крест», погрешности аппроксимаций которых равны $O\left(h^{2}\right)$. Проведено сравнение расчетов задачи переноса на основе предложенной схемы с результатами, полученными с использованием: схемы, полученной в результате линейной комбинации центральной разностной схемы и схемы «кабаре», а также двухпараметрической разностной схемой третьего порядка точности.

Ключевые слова: схема «кабаре», схема «крест», центрально-разностная схема, двухпараметрическая разностная схема, точность разностной схемы.

\section{Авторы:}

Сухинов Александр Иванович, Донской государственный технический университет (344000, Ростов-на-Дону, пл. Гагарина, 1), доктор физико-математических наук, профессор, заведующий кафедрой, sukhinov@gmail.com, ORCID: 0000-0002-5875-1523

Чистяков Александр Евгеньевич, Донской государственный технический университет (344000, Ростов-на-Дону, пл. Гагарина, 1), доктор физико-математических наук, профессор, cheese_05@mail.ru

\footnotetext{
* Исследование выполнено при финансовой поддержке РФФИ в рамках научного проекта № 19-07-00623.
} 
Кузнецова Инна Юрьевна, Южный федеральный университет (344006, Ростов-на-Дону, ул. Большая Садовая, 105/42), старший преподаватель, ikuznetsova@sfedu.ru, ORCID: 0000-00031996-1605

Проценко Елена Анатольевна, Таганрогский институт имени А.П. Чехова (филиал) Ростовского государственного экономического университета (РИНХ) (347936, ул. Инициативная, 48), кандидат физико-математических наук, доцент, eapros@ rambler.ru

Белова Юлия Валерьевна, Донской государственный технический университет (344000, Ростов-на-Дону, пл. Гагарина, 1), кандидат физико-математических наук, yvbelova@ yandex.ru 